\title{
Yoğun bakım ünitesinde çalışan sağlık personellerinin enfeksiyon kontrol önlemleri hakkındaki bilgi düzeyinin değerlendirilmesi
}

\section{Assessment of knowledge levels of health care professionals working at intensive care units about infection control measures}

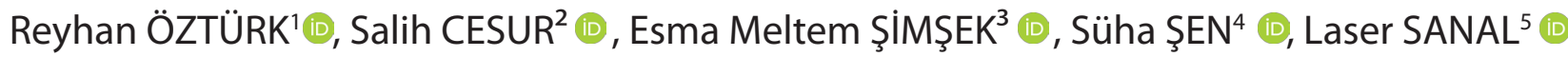

'Keçiören Eğitim ve Araştırma Hastanesi, Enfeksiyon Hastalıkları ve Klinik Mikrobiyoloji Kliniği, Ankara/TÜRKIYE ${ }^{2}$ Ankara Eğitim ve Araştırma Hastanesi, Enfeksiyon Hastalıkları ve Klinik Mikrobiyoloji Kliniği, Ankara/TÜRKIYE ${ }^{3}$ Yıldııım Beyazıt Üniversitesi, Yenimahalle Eğitim ve Araştırma Hastanesi, Anesteziyoloji Kliniği, Ankara/TÜRKIYE ${ }^{4}$ Yüksek Ihtisas Eğitim ve Araştırma Hastanesi, Enfeksiyon Hastalıkları ve Klinik Mikrobiyoloji Kliniği, Ankara/TÜRKIYE ${ }^{5}$ Türkiye Yüksek Ihtisas Eğitim ve Araştırma Hastanesi, Mikrobiyoloji Laboratuvarı, Ankara/ TÜRKIYE

\section{Öz}

Amaç: Bu çalışmada Ankara ilinde dört eğitim ve araştırma hastanesinin yoğun bakım ünitesinde çalışan sağlık personelinin enfeksiyon kontrol önlemleri hakkındaki bilgi düzeyinin eğitim öncesi ve eğitim sonrasında değerlendirilmesi ve bilgi düzeylerini etkileyebilecek faktörlerin belirlenmesi amaçlanmıştır.

Gereç ve Yöntemler: Çalışmaya Mart-Nisan 2015 tarihleri arasında Ankara Numune Eğitim ve Araştırma Hastanesi, Ankara Eğitim Araştırma Hastanesi, Dr. Zekai Tahir Burak Kadın Sağlığı Eğitim Araştırma Hastanesi, Türkiye Yüksek İhtisas Eğitim ve Araştırma Hastanesi yoğun bakımlarında çalışan ve çalışmaya katılmayı kabul eden doktor ve hemşireler dahil edilmiştir. Enfeksiyon kontrol önlemleri ile ilgili on adet soruyu içeren bir anket formu çalışmaya katılmak isteyen sağlık personeline (doktor ve hemşire) uygulanmış, bir ay sonra enfeksiyon kontrol önlemlerine ilişkin bir eğitim verildikten sonra aynı anket formu uygulanarak eğitim sonrasındaki değişiklikler istatistiksel olarak değerlendirilmiştir. Çalışmaya toplamda 164 sağlık çalışanı dahil edilmiştir.

Eğitim öncesi ve eğitim sonrasındaki anket formuna verilen yanıtlar Excel programına girilmiş ve SPSS (Statistical Package for the Social Sciences) 15.0 veri analizi programı ile istatistiksel değerlendirmeler gerçekleştirilmiştir. $P \leq 0.05$ değeri istatistiksel olarak anlamlı kabul edilmiştir.

Bulgular: Eğitim öncesi başarı oranı \%72 iken, eğitim sonrası başarı oranı \%83'e yükseldi, doğru cevap sayısı eğitimden önce ortalama sekiz iken (1-10), eğitimden sonra dokuz (4-10) olarak saptandı ve bu fark istatiksel olarak anlamlı idi ( $p=0.00)$. Sağlık personelinin enfeksiyondan korunma önlemleri hakkındaki bilgisi eğitimden sonra anlamlı olarak artmıştır. Daha önceki meslek hayatında eğitim alanların bilgisi almayanlara oranla anlamlı olarak yüksek çıkmıştır. Her iki cinste ve tüm yaş gruplarında eğitimle bilgi düzeyinin arttığı saptanmıştır.

Sonuç: Sonuç olarak, sağlık personelinin sürekli hizmet içi eğitimlerle bilgilerinin yenilenmesi ve güncellenmesi, bunun yanı sıra eğitim öncesi ve sonrasında uygulanacak testlerle değerlendirilmesinin sağlık hizmetleriyle ilişkili enfeksiyonların önlenmesinde yararlı olacağı görüşündeyiz.

Anahtar kelimeler: hastane enfeksiyonları; anket; enfeksiyon kontrol önlemleri; eğitim

Sorumlu Yazar*: Salih Cesur, Ankara Eğitim ve Araştırma Hastanesi, Enfeksiyon Hastalıkları ve Klinik Mikrobiyoloji Kliniği, Ankara/TÜRKIYE E-posta: scesur89@yahoo.com

ORCID: 0000-0003-4960-7375

Gönderim: 28.06.2017 Kabul: 08.09.2017

Doi: $10.18663 /$ tjcl.323810 


\begin{abstract}
Aim: The aim of this study is to assess knowledge levels of intensive care unit staff working at four training and research hospitals in Ankara about infection prevention measures before and after receiving training, and to determine the factors which will affect knowledge levels about infection prevention measures.
\end{abstract}

\begin{abstract}
Material and Methods: Doctors and nurses who work at intensive care units in Ankara Numune Training and Research Hospital (TRH), Ankara TRH, Dr. Zekai Tahir Burak Women's Health TRH and Ankara Turkey High Speciality TRH participated voluntarily in the study between March-April 2015. A questionnaire comprising ten questions about infection prevention measures was administered to healthcare professionals who volunteered to participate in the study (doctors and nurses), and then participants received a training regarding infection prevention measures, after the training, the same questionnaire was administered in order to evaluate the differences statistically. One hundred-sixty four health care workers were included in the study.

Answers given to the questionnaire items before and after the training were listed in Excel program and statistical analysis was carried out with SPSS 15.0 (Statistical Package for the Social Sciences) data analysis program. Value of $\mathrm{p} \leq 0.05$ was considered as statistically significant.
\end{abstract}

Results: While the success rate was $72 \%$ before the training, it reached to $83 \%$ after the training, the average number of correct answers was eight before the training (1-10), after the training, the average number of correct answers was nine (4-10) and statistically significant difference was observed $(p=0.00)$. Knowledge levels of health care professionals about infection prevention measures significantly increased after the training. Those who have received such training in their earlier professional life had statistically higher knowledge levels compared to those who have not received such training earlier in their career. It was observed that knowledge level increased through training in both genders and in every age group.

Conclusion: As a result of the renewal of knowledge with continuous training of health personnel and updating services as well as evaluating the training by using the tests before and after the training is an effective approach to the prevention of infections associated with healthcare associated infections.

Keywords: health-care associated infections; survey; infection control measures; training

\section{Giriş}

Sağlıkla ilişkili enfeksiyonlar (nozokomiyal enfeksiyonlar, hastane enfeksiyonları) tüm dünyada ve ülkemizde önemli bir sağlık sorunudur. Hastane enfeksiyonlarının kontrolünde en önemli bileşenlerden birisi sağlık personelinin hizmet içi eğitimidir [1].

Yoğun bakım üniteleri nozokomiyal enfeksiyonların en sık görüldüğü hastane birimleridir. Yoğun bakımda yatan hastalarda mortalite, morbidite ve tedavi maliyeti oranları diğer kliniklere göre daha yüksektir. Bu nedenle tüm hastanlerde ve yoğun bakım ünitelerinde yazılı bir enfeksiyon kontrol programı olmalıdır. Enfeksiyon kontrol programının en önemli bileşeni tüm sağlık personelinin belirli aralıklarla bu konuda eğitimidir [1]. Bu çalışmada Ankara ilindeki Numune Eğitim ve Araştırma Hastanesi $(E A H)$, Ankara EAH, Dr Zekai Tahir Burak Kadın Sağlığı EAH ve Ankara Türkiye Yüksek İhtisas EAH' de yoğun bakım ünitesinde çalışan sağlık personelinin enfeksiyon kontrol önlemleri hakkındaki bilgi düzeyinin eğitim öncesi ve eğitim sonrasında değerlendirilmesi ve bilgi düzeylerini etkileyebilecek faktörlerin belirlenmesi amaçlanmıştır.

\section{Gereç ve Yöntemler}

Çalışmaya Mart-Nisan 2015 tarihleri arasında Ankara Numune Eğitim ve Araştırma Hastanesi (EAH), Ankara EAH, Dr Zekai Tahir Burak Kadın Sağlığı EAH ve Ankara Türkiye Yüksek İhtisas EAH de yoğun bakımlarda çalışan ve çalışmaya katılmayı kabul eden sağlık personeli (doktor ve hemşireler) dahil edilmiştir. Enfeksiyon kontrol önlemleri ile ilgili on adet soruyu içeren bir anket formu çalışmaya katılmak isteyen sağlık personeline uygulanmış, bir ay sonra enfeksiyon kontrol önlemlerine ilişkin bir eğitim verildikten sonra aynı anket formu uygulanarak eğitim sonrasındaki değişiklikler istatistiksel olarak değerlendirilmiştir. Çalışmaya başlangıçta 272 yoğun bakım çalışanı katılmış ve bu personele on sorudan oluşan anket formu uygulanmıştır, ancak eğitim sonrası ankete katılmayan 108 kişi çalışma dışında bırakılarak hem eğitim öncesi hem de eğitim sonrası anketi cevaplandıran toplam 164 sağlık çalışanı çalışmamıza dahil edilmiştir. Bu anket çalışması için Türkiye Kamu Hastaneleri Birliği Ankara 1. Bölge Genel sekreterliğinden resmi izin alınmıştır.

Eğitim konusu hastane enfeksiyonlarının önemi, el yıkama, standart önlemler (eldiven, maske ve önlük giyilmesi gereken durumlar vb) ve izolasyon önlemleri (temas, damlacık ve solunum) ve bu önlemlerin alınmasını gerektiren infeksiyon hastalıklarından (örneğin MRSA infeksiyonunda temas izolasyonu, grip infeksiyonunda damlacık izolasyonu vb.) oluşmaktaydı. Eğitim aynı Enfeksiyon Hastalıkları Uzmanı tarafından, belirli günlerde 272 kişiye, 15-20 arası gruplar halinde, günde en fazla 1 saat olacak şekilde, toplam 18 saat süreyle verildi.

Tüm gruplarda eğitim öncesi çoktan seçmeli 10 sorudan oluşan 
ön test (pretest) uygulandı. Daha sonra aynı eğitimi alan kişilere ön testteki sorular ile aynı olan eğitim sonrası (son test) soru anketi uygulandı. Eğitim öncesi test uygulanmayanlar veya eğitim sonrası teste katılmayanlar çalışma dışı bırakıldı.

Araştırmada kullanılan soru anketi eğitimlerde anlatılan hastane enfeksiyonları kontrolüne yönelik alınması gereken önlemleri (el yıkama, maske, önlük takılması ve izolasyon önlemlerini) içermekteydi. (Ek 1. Anket soruları).

Eğitim öncesi ve eğitim sonrasındaki anket formuna verilen yanıtlar Excel programına girildi ve SPPS 15.0 programı ile istatistiksel değerlendirmeler gerçekleştirildi. Eğitim öncesi ve eğitim sonrasındaki istatistiksel değerlendirmelerde sırasıyla; Npar test, Wilcoxon signed ranks test, Mann-Whitney $U$ test, Kruskal-Wallis ve Chi-Square testleri uygulandı. $\mathrm{P} \leq 0.05$ değeri istatistiksel olarak anlamlı kabul edildi.

\section{Bulgular}

Çalışmaya dahil edilen 164 sağlık çalışanının 14'ü $(\% 8,5)$ doktor, 150 tanesi (\%915) hemşire idi. Ankete katılanların yaş aralığı 20-47 $(29 \pm 6,4)$ idi. Çalışmaya katılan gönüllülerin $130(\% 79,3)^{\prime} u$ kadın, 34 (\%20,7)'ü erkekti.

Eğitim sonundaki ankete katılım oranının düşüklüğünün nedenleri; çalışmaya katılanların iş yoğunluğu veya ankete katılım için isteksiz oluşu, başarısız olma korkusu vb. durumlardan kaynaklanabilir. Çalışmaya katılan sağlık personeline ait nitel değişkenler Tablo 1'de verilmiştir.

\begin{tabular}{|c|c|c|}
\hline Değişkenler & Kategori & Sayı (\%) \\
\hline \multirow{3}{*}{ Yaş aralığı } & 20-30 yaş & $88(53,7)$ \\
\hline & $30-40$ & $62(36,6)$ \\
\hline & 40 yaş üzeri & $14(9,7)$ \\
\hline \multirow{4}{*}{ Eğitim durumu } & Lise & $33(20,1)$ \\
\hline & 2 yıllık üniversite & $43(26,2)$ \\
\hline & 4 yıllık üniversite & $74(45,1)$ \\
\hline & 6 yıllık üniversite & $14(8,5)$ \\
\hline \multirow{2}{*}{$\begin{array}{l}\text { Daha önce hastane } \\
\text { enfeksiyonları kontrolü eğitimi }\end{array}$} & Eğitim alanlar & $146(89,0)$ \\
\hline & Eğitim almayanlar & $18(11,0)$ \\
\hline \multirow{2}{*}{ İş memnuniyeti } & $\begin{array}{l}\text { İşinden memnun } \\
\text { olanlar }\end{array}$ & $119(72,6)$ \\
\hline & $\begin{array}{l}\text { İşinden memnun } \\
\text { olmayanlar }\end{array}$ & $45(27,4)$ \\
\hline \multirow{4}{*}{$\begin{array}{l}\text { Meslekteki toplam çalışma } \\
\text { süresi (yıl) }\end{array}$} & 2 yıldan az & $22(13,4)$ \\
\hline & 2-5 yıl arası & $42(25,6)$ \\
\hline & 5-10 yıl arası & $52(31,7)$ \\
\hline & 10 yıl ve üzeri & $48(29,3)$ \\
\hline \multirow{3}{*}{$\begin{array}{l}\text { Yoğun bakımda çalışma } \\
\text { süresi }\end{array}$} & 2 yıldan az & $45(27,4)$ \\
\hline & 2-5 yıl arası & $72(43,9)$ \\
\hline & & $47(28,7)$ \\
\hline
\end{tabular}

Çalışmamızda eğitim sonrasında doğru cevap verme oranında istatistiksel olarak anlamlı artış saptandı ( $p=0.00$ ) (Tablo 2).

\begin{tabular}{|c|c|c|}
\hline & $\begin{array}{l}\text { Eğitimden } \\
\text { önce }\end{array}$ & $\begin{array}{l}\text { Eğitimden } \\
\text { sonra }\end{array}$ \\
\hline $\begin{array}{l}\text { Başarı Oranı Kötü (\%70'in Altında } \\
\text { Doğru Cevap) }\end{array}$ & $\% 34,2$ & $\% 16,4$ \\
\hline Başarı Oranı orta (\%70-80 doğru cevap) & $\% 29.3$ & $\% 27,5$ \\
\hline Başarı Oranı iyi (\%90-100 doğru cevap) & $\% 36,6$ & $\% 56,1$ \\
\hline
\end{tabular}

Başarı oranı daha önceden eğitim aldığını belirten grupta ( $p=0.001$ ) ve işini severek yaptığını belirten grupta daha yüksek idi ( $p=0.00$ ). Başarı ortalaması kadınlarda eğitim öncesi $\% 89,2$ iken, erkeklerde \%56,5 idi ve bu fark istatiksel olarak anlamlı saptandı. ( $p=0.011)$. Eğitimden sonra kadınlarda doğru cevap sayısında yüzde değişim 11,1 lik bir değer olarak saptanırken, erkeklerde 20,0'ık bir yüzde değişim saptandı ve bu fark istatiksel olarak anlamlı saptand $(\mathrm{p}=0.015)$.

Eğitimden önce yaşla birlikte doğru cevap sayısında artış mevcuttu ve bu istatiksel olarak anlamlı saptandı. ( $p=0.037$ ). Yaşla birlikte eğitim öncesi ve sonrasındaki yüzde değişim incelendiğinde anlamlı bir fark saptanmadı $(p=1.00)$.

Eğitimden önce test başarısı açısından hemşire ve doktorlar arasında anlamlı bir fark saptanmadı. Eğitime yanıt açısından da doktor ve hemşireler arasında eğitim öncesi ve sonrası arasında anlamlı bir fark saptanmadı ( $p=0.881$ ). Çalışma süresi ve yoğun bakımda çalışma süresinin eğitimden önce test başarısında anlamlı bir farka neden olmadığı, aynı şekilde çalışma süresi ve yoğun bakımda çalışma süresi açısından eğitim öncesi ve sonrası anlamlı bir olmadığı saptandı.

Eğitim düzeyine göre karşılaştıııldığında gruplar arasında eğitimden alınan fayda açısından bir fark saptanmadı ( $p=0.282$ ).

\section{Tartışma}

Sağlık hizmetleriyle ilişkili enfeksiyonlar (eski adıyla hastane kaynaklı enfeksiyonlar) hala yoğun bakım ünitelerinde çok sık görülmekte ve bu ünitelerin en önemli problemi haline gelmektedir. Yine bu enfeksiyonların kritik hastalarda mortalite ve morbiditeyi arttırdığı hastanede yatış süresi ve maliyeti de arttırdığı bilinmektedir [2].

Sağlıkhizmetleriyle ilişkilienfeksiyonlar hasta güvenliği ile ilgili başııa sorunlardandır. Birleşik Devletlerde hastane kaynaklı enfeksiyonlar ölüm nedenleri arasında 6. sırada gelmektedir ve her 100 kabulde 4,5 oranında görülmekte ve yaklaşık 99.000 ölümle ilişkilidir [3]. Ülkemizde yapılan bir çalışmada nozokomiyal enfeksiyon 1000 yoğun bakım ünitesi gününde 22,1 olarak saptanmıştır [4]. 
Yirmi üç ülkeden 66 hastanenin katıldığı bir çalışmada hastaneye yatan hastaların \%7,1'inde hastane enfeksiyonu geliştiği saptanmış. Yoğun bakım ünitelerinde ise bu oran \%28,1 şeklinde oldukça yüksek olduğu görülmüş [5].

Hastane enfeksiyonlarını önlemek için enfeksiyon kontrol önlemlerinin sağlık çalışanları tarafından çok iyi biliniyor ve uygulanıyor olması ve hizmetiçi eğitimlerle bu bilgilerin güncel tutulması gerekmektedir. Çalışmamızda katılımcıların \%89'u daha önceden hastane infeksiyonlarının kontrolü hakkında bir eğitim aldığını söylerken, \%11'i konu ile ilgili daha önce herhangi bir eğitim almadığını ifade etti. Demirdal ve ark.'nın yaptığı bir çalışmada hemşirelerin \%72'si, asistan doktorların ise \%58,7'si hastane enfeksiyonlarının kontrolü hakkında eğitim aldığını ifade etmiş̧tir [6]. Aynı çalışmada el yıkama konusunda eğitim ve bilgiyi hemşirelerin, en çok okuldan $(\% 24,7)$ ve Enfeksiyon Kontrol Komitesinden $(\% 14,7)$, asistan doktorların ise okuldan (\%24) ve çalıştıkları birimden $(\% 14,7)$ aldıklarını saptamışlar. Demir ve ark'nın yaptığı bir çalışmada, katılımcıların \%80,4'ü el hijyeni konusunda eğitim aldığını belirtirken, \%19,6'sının bu konuda eğitim almadığı görülmüştür. El yıkama konusunda, katılımcıların \%59'u sağlık çalışanlarından (Enfeksiyon Kontrol Komitesi), \%30'u Sağlık Bakanlığı internet sitesinden bilgi aldığını belirtmiştir [7].

Helder ve ark. [8], yaptıkları çalışmada eğitim programı ile sağlık çalışanlarının el hijyenine uyumlarının arttığını, hastane kaynaklı kan dolaşımı enfeksiyonlarının azaldığını saptamışlardır. Pekuslu ve ark. izolasyon önlemlerine ilişkin eğitim alan doktor ve hemşirelerin uyumlarının daha iyi olduğunu belirlemişlerdir [9].

Ege üniversitesinde yapılan bir çalışmada 1286 temas (914 yüzeysel, 372 invaziv) değerlendirildiğinde, el hijyenine uyum \%5,9 gibi düşük bir oranda saptanmıştır [10].

Sunduğumuz çalışmada eğitim öncesi başarı oranının (\%72), eğitim sonrasında arttığı ( \%83) ve aradaki istatiksel olarak anlamlı olduğu saptandı. Wisnievski ve ark.'nın yaptığı bir çalışmada enfeksiyon kontrolü konusundaki eğitim ve toplantıların doktorlarda ve yardımcı sağlık personelinde enfeksiyon kontrolü hakkındaki bilgileri anlamlı olarak arttırdığı saptanmış [11]. Sunduğumuz çalışmada da Wisnievski ve ark. çalışmasında olduğu gibi sağlık personelinde her iki cinste ve tüm yaş gruplarında eğitimle bilgi düzeyinin arttığı saptandı. Ancak, çalışmamızda daha önceki meslek hayatında eğitim alanların eğitim sonrası uygulanan testeki başarı oranı anlamlı oranda yüksekti.

İspanya'da iki pediatrik yoğun bakım ünitesinde çalışan sağlık personelinde yapılan çalışmada, 20 dakika süreyle uygulanan bir eğitim programının sağlık personelinin bilgi düzeyi ve kateter ilişkili kan dolaşımı enfeksiyonu insidansının üzerine etkisi araştırılmıştır. Çalışmada sağlık çalışanlarının kateter ilişkili kan dolaşımı enfeksiyonunun önlenmesi ile ilgili bilgileri, eğitim öncesi ve sonrası 12 soruyu içeren bir anketle değerlendirilmiş. Tüm sağlık çalışanlarına herbir yoğun bakım şiftinde 20 dakikalık bir program sunulmuştur. Sadece 20 dakikalık bir eğitimin yoğun bakım sağlık çalışanlarının kateter ilişkili kan dolaşımı enfeksiyonu ile ilgili bilgilerini anlamlı derecede düzelttiği fakat enfeksiyon insidansında azalmayı sağlamak için yeterli olmadığı saptanmıştır [12].

Adana'da Başkent Üniversitesi Adana Araştırma ve Uygulama Hastanesi, Çukurova Üniversitesi Tıp Fakültesi Balcalı Hastanesi ileT.C. Sağlık Bakanlığı Adana Numune Eğitim ve Araştırma Hastanesinin yaptığı bir çalışmada hemşirelerin hastane enfeksiyonları ile ilgili eğitim alma durumları incelendiğinde \%63,3'ünün eğitim aldıkları saptanmıştır. Çalışmaya katılan 210 hemşirenin verdikleri doğru cevap sayıları ile hastane enfeksiyonu konusunda eğitim alıp- almama durumları incelendiğinde; eğitim alan hemşirelerde doğru cevap verme oranı, eğitim almayanlardan anlamlı oranda yüksek saptanmıştır [13]. Sunduğumuz çalışmada da bu çalışmayla benzer şekilde daha önceki meslek hayatlarında eğitim alanların değerlendirme testinde doğru cevap verme oranı, eğitim almayanlara göre anlamlı oranda yüksekti. Ayrıca, çalışmamızda personelin sorulara doğru cevap verme oranının eğitimden sonra eğitim öncesine göre istatistiksel olarak anlamlı oranda arttığını saptadık. Bu durum eğitimlerin belirli periyotlarla tekrarlanmasının son derece yararlı ve gerekliliği olduğunu göstermektedir.

Coopersmith ve ark.'nın yaptığı bir çalışmada toplam 42 sağlık çalışanına kateter ilişkili kan dolaşımı enfeksiyonlarının azaltılması ile ilgili verilen eğitim sonucunda; enfeksiyon oranının 1000 kateter gününde 11,8'den 3,7'ye gerilediği ve eğitim öncesi periyoda göre \%66 oranında azalma olduğu tespit edilmiştir [14].

Mc Alearney ve ark.'nın santral kateter ilişkili kan dolaşımı enfeksiyonlarını önleme metotları ile ilgili yaptıkları bir çalışmada, başarıyı etkileyen faktörler eğitim, yönetim, veri ve uyum bulunmuş. Enfeksiyon kontrol çalışanlarının yeni bir perspektifle bakışının sağlanmasının başarıyı arttırdığı saptanmış [15].

Mısır'da yapılan bir çalışmada yoğun bakım ünitelerinde çalışan 125 hemşirenin enfeksiyon kontrolü ile ilgili davranış biçimleri yapılan bir öntest anketle değerlendirilmiş. Daha sonra bu personele power point ve video sunumuyla bir eğitim verilmiş ve eğitim sonunda hemşirelerin enfeksiyon kontrolü ile ilgili bilgileri yeniden değerlendirilmiş. Hemşirelerin hastane enfeksiyonları ilgili bilgilerinin eğitim sonrası anlamlı derecede arttığı saptanmıştır. Yine enfeksiyon kontrol önlemlerinin kendilerini enfeksiyonun bulaşından önlediğine olan inançları \%65,6 dan 79,2 ye yükseldiği saptanmış. Multidisipliner ve katılımcı eğitim modelleri ile enfeksiyon kontrol önlemlerinin öneminin çok daha iyi anlaşılıp uygulanabileceği sonucuna varılmış [16]. 
Sunduğumuz çalışmada eğitimden önce yaşla birlikte doğru cevap sayısında artış mevcuttu ve bu istatiksel olarak anlamlı idi fakat çalışma süresinin enfeksiyon kontrol önlemleri hakkındaki bilgi düzeyi üzerine anlamlı bir etkisi yok idi. Çalışmamızın aksine Ho ve ark'.nın yaptığı bir çalışmada yaş grupları arasında el hijyeni konusundaki bilgi ve uyum arasında anlamlı bir fark saptanmazken, çalışma süresi arttıkça el hijyeni ile ilgili bilgi ve uyumda anlamlı bir artış saptanmıştır. Hemşirelerin el hijyenine uyum konusundaki bilgi ve uygulamalarının iyi olduğu, hemşirelerin çalışma yıllarının bu uyumu arttırdğı belirlenmiştir[17].

Gatell ve ark. yaptıkları çalışmada hemşirelerin ventilatör ilişkili pnömoni önleme metotları hakkındaki teorik bilgilerini ve pratik uygulamalarını bir eğitim öncesi ve sonrasında değerlendirmişler. Eğitim sonrası teorik bilgilerde, subglottik sekresyonların aspirasyonunun nasıl önleneceği ve oral hijyen hakkındaki bilgilerinde anlamlı bir artış saptanmış ve ViP insidansının eğitim sonrası anlamlı derecede azaldığı belirlenmiştir (1000 ventilatör gününde 4,6 dan 3,1'e). Benzer şekilde bizim çalışmamızda da eğitim sonrası doğru cevap sayısında anlamlı bir artış saptanmıştır. Bu çalışmada, katılımcıların \%89,6'sı kateter aspirasyonundan önce ve sonra el yıkamanın gerekli ve önemli olduğunu bilmesine rağmen sadece \%98'inin kateter takmadan önce ellerini yıkadığı, taktıktan sonra ise el yıkama oranının \%34,1'e yükseldiği saptanmıştır. Araştırmacılar bilgide artmanın her zaman uyumda artışa neden olmadığı ifade etmişlerdir [17].

Lin ve ark. yaptıkları 133 katılımcının olduğu anket çalışmalarında, yoğun bakım lisansı olan ve kıdemli olan hemşirelerde VIP önleme konusunda daha bilgili olduklarını saptamışlardır [19]. Sunduğumuzçalışmada, bu çalışmanın aksine sağlıkpersonelinde çalışma süresi ve öğrenim süreleri test başarısı açısından anlamlı bir farka neden olmadı.

Gülhane Askeri Tıp Fakültesi Eğitim Hastanesi'nde yoğun bakım ünitelerinde yapılan bir anket çalışmasında büyük yaş grubundaki hemşireler küçük yaş grubundaki hemşirelere göre, eğitimlerin daha az etkin olduğunu bildirmişlerdir. Aynı çalışmada hemşirelerin hizmet içi eğitimlerden beklentileri oldukça yüksek düzeyde olduğu da saptanmıştır [20].

Finlandiya'da yapılan bir çalışmada üçüncü basamak yoğun bakım ünitesinde çalışan hemşirelerde ventilatör ilişkili pnömoniyi önlemek için verilen uygulamalı bir eğitimden sonra, bilgi ve becerilerinin anlamlı derecede arttığı saptanmış [21].

İran'da 150 yoğun bakım hemşiresinin katıldığı bir çalışmada el hijyeni ve enfeksiyon kontrolü konusunda hemşirelerin iş deneyimleri ve önceki eğitimlerinin bilgilerini belirleyen en önemli faktör olduğu görülmüş. Yine bu çalışmadaki bulgular katılımcıların \%68'inin el hijyeni konusunda sürekli eğitime ihtiyacı olduğu saptanmış. Bu çalışmada katılımcıların \%15,9'u daha önceden el hijyeni ile ilgili bir eğitime katılmadıklarını ifade etmişler [22].

Sodjj ve ark.'nın yaptığı 100 hemşirenin katıldığı ve 40 sorunun sorulduğu bir anket bir çalışmasında enfeksiyon kontrol önlemleri hakkında hemşirelerin bilgi düzeylerinin \%5'inde çok iyi (\%90'ın üzerinde doğru cevap), \%37'sinde iyi (\%80-90 doğru cevap), \%40'ında orta (\%70-80 doğru cevap) ve \%18'inde kötü (\%70'in altında doğru cevap) olduğu saptanmış [23]. Sunduğumuz çalışmada, katılımcıların \%34.2'sinin başarı oranı kötü, \%29,3'ünün orta, \%36,6'sının ise iyi olduğu saptandı. Başarı oranı daha önceden eğitim aldığını belirten grupta ve işini severek yaptığını belirten grupta daha yüksek idi. Çalışmamızda meslek grupları arasında enfeksiyon kontrol önlemleri hakkındaki bilgi düzeyleri açısından bir fark saptanmadı. Benzer şekilde Alkubati ve ark.'nın yaptığı bir çalışmada 40 doktor ve 60 hemşirenin katıldığı ve santral venöz kateter ilişkili enfeksiyon önleme ile ilgili bilgilerinin ölçüldüğü bir çalışmada iki meslek grubunun bilgi düzeyleri arasında anlamlı bir fark saptanmamıştır [24].

Demir ve ark.'nın yaptığı bir çalışmada genel olarak sorulara doğru cevap verme oranı açısından meslekler ve çalışılan birimler arasında fark saptanmamış fakat yeni mezunların daha fazla soruyu doğru cevapladığı gözlenmiştir [25].

İtalya'da Orsi ve ark.'nın yaptığı bir çalışmada enfeksiyon kontrol programının yoğun bakım çalışanlarına anlatıldıktan sonra hastane kaynaklı enfeksiyonların insidansında ve mortalitesinde azalma görüldüğü tespit edilmiş [26].

Diker çalışmasında hizmet içi eğitim alma durumları ile bilgi puanı arasında herhangi bir ilişki bulamadığını belirtmiştir [27]. Sunduğumuz çalışmada Diker ve ark. [28] çalışmasının aksine daha önceden hizmet içi eğitim alanlarda başarı düzeyi daha yüksek saptandı.

Sunduğumuz çalışmada, sağlık personelinin enfeksiyondan korunma önlemleri hakkındaki bilgisi her iki cinsiyete ve tüm yaş gruplarında eğitimden sonra arttığı saptandı. Elde ettiğimiz bu sonuç enfeksiyon kontrolüne yönelik hizmet içi eğitimin yararını ve gerekliliğini göstermektedir.

\section{Sonuç}

Sağlık personeline sağlık hizmetleriyle ilişkili enfeksiyonlar ve korunma yöntemleri hakkında belirli periyotlarla eğitimlerin verilmesi, eğitimlerin güncellenmesi, bunun yanı sıra eğitim öncesi ve sonrasında yapılacak testlerle verilen eğitimlerin değerlendirilmesinin yararlı olacağı görüşündeyiz.

\section{Maddi Destek ve Çıkar illişkisi}

Çalışmayı maddi olarak destekleyen kişi/kuruluş yoktur ve yazarların çıkara dayalı bir ilişkisi yoktur. 


\section{Kaynaklar}

1. Yüceer S, Demir SG. Yoğun bakım ünitesinde nozokomiyal enfeksiyonların önlenmesi ve hemşirelik uygulamaları. Dicle Tıp Derg 2009; 36: 226-32.

2. Zaragoza R, Ramirez P, Lopez-duego MJ. Nasocomial infectıons in intensive care units. Enferm Infec Microbiol Clin 2014; 32: 320-27.

3. Peleg AY, Hooper DC. Hospital-acquired infections due to Gramnegative bacteria. N Engl J Med 2010; 13; 362: 1804-13.

4. Tükenmez Tigen E, Doğru A, Koltka EN, Ünlü C. Device-associated nasocomial infection rates and distribution of antimicrobial resistance in a medical-surgical intensive care unit in Turkey. Jpn $J$ Infect Dis 2014; 67: 5-8.

5. Zarb P, Coignard B, Griskeviciene J et al. The European Centre for Disease Prevention and Control (ECDC) pilot point prevalence survey of healthcare-associated infections and antimicrobial use. www eurosurveillance org.

6. Demirdal T, Uyar S, Demirtürk N. Bir üniversite hastanesinde çalışanlarda el yıkama uygulamalarının ve bilgi düzeylerinin değerlendirilmesi. Kocatepe Tıp Derg 2007; 8: 39-43.

7. Demir NA, Kölgelier S, Küçük A, Özçimen S, Sönmez B, Saltuk L. Sağlık çalışanlarının el hijyeni hakkındaki bilgi düzeyi ve el hijyenine uyumu. Nobel Med 2013; 9: 104-9.

8. Helder OK, Brug J, Looman CWN. The impact of an education program on hand hygiene compliance and nosocomial infection incidence in an urban neonatal intensive care unit: an Intervention Study with before and after Comparison. International Journal of Nursing Studies 2010; 47: 1245-52.

9. Pekuslu S, Demirci H, Taşçıoğlu $S$ et al. Bir devlet hastanesinde çalışan hekim ve hemşirelerin izolasyon önlemlerine uyumlarının değerlendirilmesi. Beylik U, Önder Ö, Güler H, Öztürk A. III. Uluslararası Sağlıkta Performans ve Kalite Kongresi. Sözel Bildiriler Kitabı. Tedavi Hizmetleri Genel Müdürlüğü. 1. Basım. 2011; 51-62.

10. Arda B, Şenol Ş, Taşbakan Ml et al. Ege Üniversitesi Tıp Fakültesi Yoğun Bakım Ünitelerinde el temizliği kurallarına uyumun değerlendirilmesi. Yoğun Bakım Derg 2005;5: 182-86.

11. Wisniewski MF, Kim S, Trick WE, Welbel SF, Weinstein RA. Effect of education on hand hygiene beliefs and practices: a 5-year program. Infect Control Hosp Epidemiol. 2007; 28: 88-91.

12. Guembe M, Perez-Parra A, Gomez E et al. Impact on knowledge and practice of an intervention to control catheter infection in the ICU. Eur J Clin Microbiol Infect Dis 2012; 31: 2799-808.

13. Aytaç $\mathrm{N}, \mathrm{Naharcı} \mathrm{H}$, Öztunç $\mathrm{G}$. Adana'da eğitim araştırma hastanelerinin yoğun bakım hemşirelerinde hastane enfeksiyonları bilgi düzeyi. ADÜ Tıp Fakültesi Derg 2008; 9: 9-15.

14. Coopersmith CM, Rebmann TL, Zack JE et al. Effect of an education program on decreasing catheter-related bloodstream Infections in the surgical intensive care unit. Crit Care Med 2002; 30: 59-64.
15. Mc Alearney AS, Hefner JL. Facilitating central line-associated bloodstream infection prevention: a qualitative study comparing perspectives of infection control professionals and frontline staff. Am J Infect Control 2014; 42: 216-22.

16. Galal YS, Labib JR, Abouelhamd WA. Impact of an infectioncontrol program on nurses' knowledge and attitude in pediatric intensive care units at Cairo University hospitals. J Egypt Public Health Assoc 2014; 89: 22-28.

17. Ho SE, Ho CC, Hng SH, Liu CY, Jaafar MZ, Lim B. Clin Ter. Nurses compliance to hand hygiene practice and knowledge at Klang Valley hospital. 2013; 164: 407-11.

18. Gatell MRJ, Roig MS, Vian $\mathrm{OH}$ et al. Assessment of a training programme for the prevention of ventilator-associated pneumonia. British Association of Critical Care Nurses 2012; 17: 285-92.

19. Lin HL, Lai CC, Yang LY. Critical care nurses' knowledge of measures to prevent ventilator-associated pneumonia. Am J Infect Control 2014; 42: 923-25.

20. Çelen Ö, Karaalp T, Kaya S, Demir C, Teke A, Akdeniz A. Gülhane Askeri Tıp Fakültesi Eğitim Hastanesi Yoğun Bakım Ünitelerinde görev yapan hemşirelerin uygulanan hizmet içi eğitim programlarından beklentileri ve bu programlar ile ilgili düşünceleri. Gülhane Tıp Derg 2007; 49: 25-31.

21. Jansson MM, Ala-Kokko TI, Ohtonen PP, Merilainen MH, Syrjala HP, Kyngas HA. Human patient simulation education in the nursing management of patients requiring mechanical ventilation: a randomized, controlled trial. Am J Infect Control 2014; 42: 271-76.

22. Asadollahi $M$, Bostanabad MA, Jebraili $M$, Mahallei $M$, Rasooli AS, Abdolalipour M. Nurses'Knowledge Regarding Hand Hygiene and Its Individual and Organizational Predictors. J Caring Sci 2015; 4: 45-53.

23. Sodhi K, Shrivastava A, Arya M, Kumar M. Knowledge of infection control practices among intensive care nurses in a tertiary care hospital. J Infect Public Health 2013; 6: 269-75.

24. Alkubati SA, Ahmed NT, Mohamed ON, Fayed AM, Asfour HI. Health care workers' knowledge and practices regarding the prevention of central venous catheter-related infection. Am J Infect Control. 2015; 43: 26-30.

25. Demir NA, Kölgelier $S$, Küçük $A$ et al. AÇ. Sağlık çalışanlarının el hijyeni hakkındaki bilgi düzeyi ve el hijyenine uyumu. Nobel Medicus 2013; 9: 104-9

26. Orsi GB, Raponi M, Franchi C, Rocco M, Mancini C, Venditti M. Surveillance and infection control in an intensive care unit. Infect Control Hosp Epidemiol 2005; 26: 321-25.

27. Diker S. Uşak il merkezindeki hastanelerde çalışan hemşirelerin hastane enfeksiyonlarına ilişkin bilgi düzeylerinin belirlenmesi. Yüksek Lisans tezi, Afyon Kocatepe Üniversitesi Sağlık Bilimleri Enstitüsü Cerrahi Hastalıkları Hemşireliği Ana Bilim Dalı, 2003. 


\section{Ek 1. Anket Formu}

Adınız:

Cinsiyetiniz:

Yaşınız:

Göreviniz:

Öğrenim Durumunuz:

Kaç Yıldır Görev Yapıyorsunuz:

Ne Kadar Süredir Yoğun Bakımda Çalışıyorsunuz:

Daha Önce Enfeksiyon Kontrol Önlemleri İle İlgili Eğitim Aldınız Mı?

İşinizi Severek Yapıyor Musunuz?

Yoğun Bakım Ünitesinde Çalışan Personelin Enfeksiyon Kontrol Önlemleri Hakkındaki Bilgi Düzeyinin Ölçülmesi Anketi

Soru 1: Enfeksiyon Kontrol Önlemlerine Uyulmasının Ne Yararı Vardır?

A. Hastalardan Bize Enfeksiyon Bulaşmasını Engeller

B. Bizden Hastalara Enfeksiyon Bulaşmasını Engeller

C. Hastalardan Diğer Hastalara Enfeksiyon Bulaşmasını Engeller

D. Dirençli Mikroorganizmaların Yayılmasını Azaltır

E. Hepsi

Soru 2: Aşağıdaki Enfeksiyon Etkenlerinden Hangisinde Temas İzolasyonu Gerekmez?
A. Mrsa
B. Acinetobacter
C. Esbl Pozitif Klebsiella
D. E. Coli
E. P. Aeruginosa

Soru 3: Hangisi Damlacık Yoluyla Bulaşmaz?
A. Vre
B. Boğmaca
C. Ifluenza
D. Kızamıkçık

E. İnvaziv Neisseria Meningitidis Menenjiti

Soru 4: Hangisinde Solunum İzolasyonuna Gerek Yoktur?
A. Esbl Pozitif E. Coli
B. Tüberküloz
C. Su Çiçeği
D. Sars
E. Kızamık

Soru 5: Damlacık Yoluyla Bulaş Ya Da Solunum Yolu İle Bulaş İle İlgili Hangisi Yanlıştır?

A.Damlacık Enfeksiyonu İle Temasta Bulaşmanın Olması İçin Yakın Temas Gereklidir (1 Metre Veya Daha Az)
B. Damlacık Yolu İle Bulaş Küçük Partiküllü Parçacıklar İle Olur.

C. Solunum İzolasyonu Gerektiren Hastalıklarda Partiküller Havada Asılı Kalır Ve Hava Akımıyla Uzaklara Yayılabilir.

D. Solunum Yolu İle Bulaşan Hastalıklarda Önlem Alınmazsa Aynı Odada Olmayan Hastalara Da Bulaş Olabilir.

E. Solunum Yolu Ille Bulaş Küçük Partiküllü Parçacıklar İle Olur. Soru 6: Temas İzolasyonunda Hangi Ekipmana İhtiyaç Yoktur?
A. N95 Maske
B. Eldiven
C. Önlük
D. El Antiseptiği
Soru 7: Eller Ne Zaman Yıkanmalıdır?
a. Hasta ile temastan önce
b. Hasta ile temastan sonra
c. Hastaya yapılan girişimler sonunda
d. Eldiven çıkardıktan sonra
e. Hepsi

E. Hastanın Kan Ya Da Vücut Sıvısı İhtimali Varsa Önlük

Soru 8: Hangisinde N 95 ya da FFP3 maske kullanmak gerekir?
a. MRSA
b. VRE
c. Su çiçeği
d. ESBL pozitif E. coli
e. Acinetobacter

Soru 9: Negatif basınçlı oda hangi izolasyon yönteminde gerekir?

a. Standart önlemler

b. Temas izolasyonu

c. Sıkı temas izolasyonu

d. Solunum izolasyonu

e. Damlacık izolasyonu.

Soru 10: Standart önlemler enfekte olup olmadığına bakılmaksızın tüm hastalarda uygulanan kontrol önlemleridir. Aşağıdakilerden hangisi standart önlem değildir?
a. Eldiven kullanılması
b. El hijyenine uyulması
c. N95 maske takılması

d. Kan ya da vücut sıvılarının sıçraması ihtimali olan işlemlerde önlük, maske, yüz ve göz koruyucusu kullanılması

e. Kontamineekipman veya araçların uygun şekilde uzaklaştıııması 